\title{
PELATIHAN CARA MEMPROMOSIKAN SEKOLAH PADA YAYASAN TIARA VERITAS DAN REKANANNYA
}

\author{
Selvi Esther Suwu \\ Fakultas Pendidikan, Universitas Pelita Harapan \\ selvi.suwu@uph.edu
}

\begin{abstract}
Abstrak
Kebutuhan akan pendidikan semakin maju, terlihat dari kuantitas sekolah yang meningkat. Bagi konsumen keadaan ini menguntungkan, karena dapat memilih sekolah dengan mudah. Akhirnya tercipta persaingan antar sekolah dan mengakibatkan jumlah siswa yang mendaftar berkurang. Hal ini membuat pihak sekolah berpikir untuk meningkatkan kualitas sekolahnya, namun kualitas bukan satu-satunya jalan untuk menarik konsumen. Konsumen mempunyai banyak pertimbangan ketika memilih sekolah untuk anaknya. Maka Yayasan Tiara Veritas bersama rekanannya (beberapa sekolah yang berlokasi di Kab.Tangerang dan Tangerang Kota) merasa perlu diperlengkapi mengenai promosi sekolah dan menghubungi Service Learning UPH sebagai rekanan kerjasama dalam Pengabdian Masyarakat. Penulis adalah dosen Pemasaran di UPH dan bersedia memberikan pelatihan mengenai promosi sekolah. Pengabdian masyarakat ini dilakukan dengan metode Pelatihan. Agar mengetahui efektifitas dari acara ini maka penulis membuat pre test dan post test. Hasilnya adalah peserta yang tadinya sudah mengerti bertambah mengerti, terutama pada bagian tips promosi peserta mengakui banyak belajar hal baru. Artinya memang sekolah bukan hanya memerhatikan kurikulum dan fasilitas secara umum tetapi pelayanan yang maksimal dari seluruh lapisan karyawan di sekolah juga perlu diperhatikan. Selanjutnya Yayasan Tiara Veritas dan rekanan meminta penulis untuk membawakan topik promosi (bagi sekolah rekanan yang tidak hadir) dan lainnya (manajemen keuangan sekolah) akan ditindaklanjuti semester depan.
\end{abstract}

Kata Kunci : Promosi sekolah, Pelatihan, Yayasan Tiara Veritas

\section{PENDAHULUAN}

Sektor pendidikan semakin maju dengan beragam kurikulum yang ada sekarang. Pendidikan formal yang diwakilkan dengan sekolah mulai dari PAUD hingga sekolah menengah atas semakin banyak dan berkembang di Indonesia. Sekolah mengutamakan pelayanan dalam menjalankan tugasnya karena memang bergerak dalam bidang jasa, jasa adalah menawarkan kegunaan atau kegiatan pada konsumen (Tjiptono, 2017). Orang tua sebagai konsumen akan memilih sekolah sesuai keinginannya, menurut (Kotler \& Armstrong, 2008) keinginan akan membentuk suatu permintaan yang mempunyai daya beli, dan ini disikapi pihak sekolah dengan memberikan pelayanan yang terbaik. Sekolah diharapkan mempunyai nilai lebih agar mampu memenuhi harapan konsumen. Nilai lebih yang biasanya dipenuhi sekolah adalah kualitas pembelajaran, namun konsumen tidak hanya memerhatikan itu saja. Yayasan Tiara Veritas dan rekanannya adalah rekanan dari UPH dalam bidang pengabdian masyarakat.

Yayasan Tiara Veritas berpartisipasi dalam memberikan layanan kepada Anak Usia Dini, dalam bentuk PAUD. Yayasan Tiara Veritas dan rekanannya belokasi di tangerang.

Ekonomi, Sosial, dan Budaya

1081 
VISI : Terwujudnya anak yang berkarakter Kreatif dan Mandiri.

MISI:

1. Mendidik anak secara optimal sesuai dengan usia

2. Mengembangkan potensi anak sejak usia dini

3. Menciptakan suasana belajar melalui bermain.

4. Meningkatkan kesadaran dan partisipasi masyarakat terhadap layanan PAUD

Sadar akan pentingnya konsumen bagi sekolah membuat sekolah berlomba-lomba menarik perhatian dengan mempromosikan sekolahnya. (Kotler et al., 2011) dalam bukunya mengatakan "Sales Promotion is short term incentives to encourage the purchase or sale of a product or service." Persaingan semakin ketat ketika membicarakan mengenai kualitas sekolah yaitu, kurikulum, fasilitas sekolah, namun ternyata konsumen berharap bukan hanya itu. Dengan demikian Tiara Veritas dan rekanannya meminta bantuan dari UPH selaku rekanan dalam bidang pendidikan yang jenjangnya lebih tinggi untuk memberikan pelatihan mengenai promosi sekolah. UPH memiliki banyak bidang studi dengan banyak dosen juga, setiap rekanan UPH yang memerlukan bantuan dalam bidang pengetahuan akan dibantu melalui dosen-dosen yang akan memberikan penyuluhan atau pelatihan.

Wadah kerjasama UPH dengan rekanannya beberapa ditampung oleh Service Learning, Service Learning merupakan suatu program yang diimplementasikan oleh Univesitas Pelita Harapan untuk mendukung visi dan misinya dalam memberikan pendidikan yang holistik kepada mahasiswanya. Dalam hal ini Service Learning berfungsi sebagai suatu metode belajar yang berguna untuk mengaplikasikan nilai dalam mata kuliah kedalam praktek pengabdian kepada masyarakat. (Christian, Siahaan, \& Wardhani, 2015)

Service Learning memberdayakan mahasiswa sebagai bagian pembelajarannya dalam mata kuliahmata kuliah tertentu yang akan menilai pengabdian masyarakat ini sebagai bagian dari tugas yang harus mahasiswa kerjakan.

Sekolah- persaingan- perlu dikenal (keberadaannya)- promosi menjadi bagian perkenalan- pentingnya pelayanan (mutu) sebagai pemasaran tersendiri.

Sekolah menurut (Van Brummelen, 2006) mengarah pada pendidikan formal dalam rangka mengembangkan potensi anak-anak dengan kasih.

Promosi adalah bagian dari bauran pemasaran, menurut (Buchari, 2005) promosi adalah suatu bentuk komunikasi agar konsumen percaya terhadap produk dan jasa yang dijual.

Promosi mempunyai bauran promosi seperti menurut (Elliott, RUNDLE-THIELE, \& Waller, 2014), the promotion mix adalah beberapa metode promosi yang terangkai untuk mempromosikan barang atau jasa. Jenis-jenis dari bauran promosi adalah advertising, public relation, sales promotion, dan personal selling.

\section{METODE}

Kegiatan Pengabdian kepada Masyarakat "Pelatihan Promosi Sekolah" ini dimulai dengan permintaan dari yayasan Tiara Veritas dan rekanannya terhadap UPH melalui Service Learning untuk salah satu dosen UPH membawakan pelatihan mengenai promosi sekolah. Setelah permintaan disetujui Service Learning menghubungi dosen sebagai pembicara pelatihan tersebut juga mulai membentuk kepanitiaan untuk mahasiswa yang bertugas untuk membantu sekaligus mengerjakan tugas salah satu mata kuliah. Setelah kepanitiaan terbentuk mulailah Service Learning dan mahasiswa bekerja mempersiapkan acara, dari menentukan tanggal kegiatan pelatihan hingga rundown acaranya. Pertemuan juga diadakan antara Service Learning, mahasiswa dan pembicara yang diadakan beberapa minggu sebelum acara, pengaturan kegiatan pelatihan dari pendaftaran peserta, susunan acara juga tugas tiap mahasiswa yang terlibat. 
RUNDOWN ACARA

\begin{tabular}{|c|c|c|}
\hline Waktu & Durasi & Aktivitas \\
\hline \multicolumn{3}{|c|}{ Rabu / 27 Maret 2019, 14.00 - 16.15 WIB } \\
\hline $\begin{array}{l}14.00- \\
14.05\end{array}$ & $5^{\prime}$ & Pembukaan dan Perkenalan \\
\hline $\begin{array}{l}14.05 \\
14.55\end{array}$ & $50^{\prime}$ & $\begin{array}{l}\text { Sesi 1 : Materi dan tanya } \\
\text { jawab } \\
\text { Cara } \\
\text { Sekolah }\end{array}$ \\
\hline $\begin{array}{l}14.55 \\
15.10\end{array}$ & 15 & Istirahat \\
\hline $\begin{array}{l}15.10 \\
16.00\end{array}$ & 50 ' & $\begin{array}{l}\text { Sesi 2 : Materi dan tanya } \\
\text { jawab } \\
\text { Cara } \\
\text { Sekolah }\end{array}$ \\
\hline $\begin{array}{l}16.00 \\
16.05\end{array}$ & 5 & $\begin{array}{l}\text { Pemberian Sertifikat dan } \\
\text { Souvenir kepada Pembicara }\end{array}$ \\
\hline $\begin{array}{l}16.05 \\
16.15\end{array}$ & 10 ' & Foto Bersama \\
\hline
\end{tabular}

Pembicara melihat acara ini baik sekali sebagai suatu pembelajaran, sehingga pembicara ingin mengetahui efektifitas dan efisiensi acara yang telah berlangsung agar pembicara tahu bahwa pelatihan yang dibawakan berguna atau tidak. Informasi mengenai efisiensi dan efektif tersebut diperoleh dari kuesioner yang dibagikan pada sebelum pelatihan (pre-test) dan akhir pelatihan (post-test).

Subyek penelitian $=$ manajemen sekolah, kepala sekolah, guru

Jumlah responden $=72$ orang, terdiri dari sekolah Yayasan Tiara Veritas dan rekanannya

Lokasi kegiatan pelatihan MYC MPR Universitas Pelita Harapan

Acara pelatihan ini dimasukkan ke You Tube, berikut adalah link kegiatan pelatihan : https://www.youtube.com/watch?v=yRKQgW4sRJ $\underline{\mathrm{w}}$ 


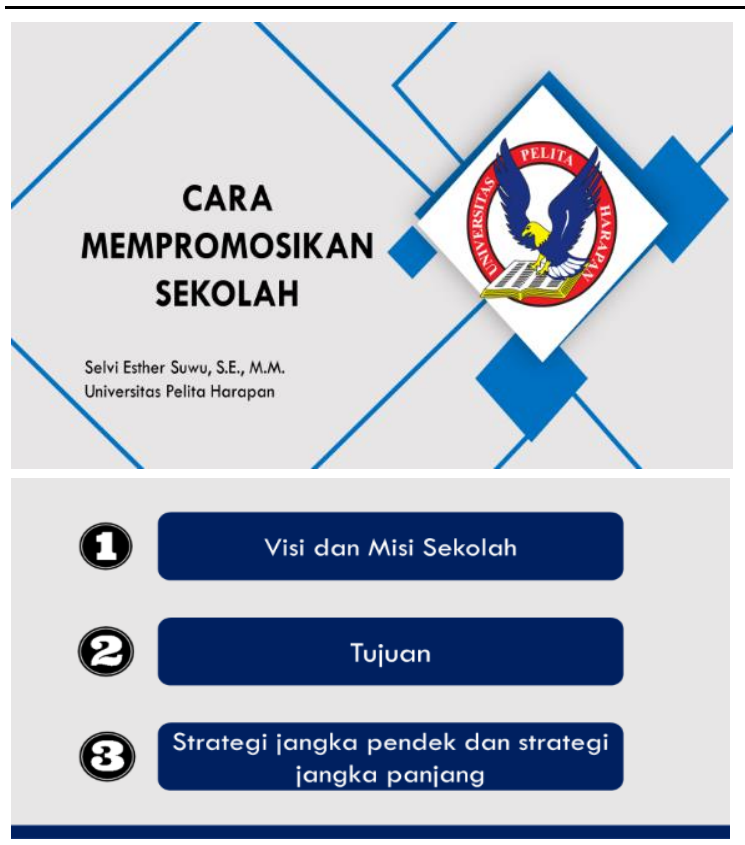

CARA PROMOSI (DALAM JASA) SEKOLAH

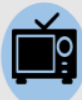

Iklan (media : TV, Radio, Media Sosial. Banner : tentang prestasi siswa)

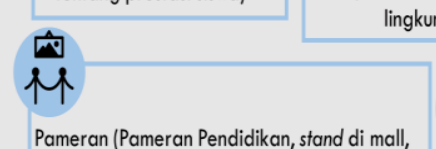
pasar modern)

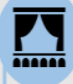

Acara (di mall: tari-tarian, di lingkungan sekolah : kegiatan seperti pramuka, Bazaar/musik di lingkungan sekolah)

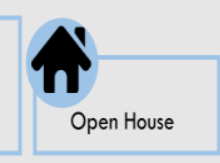

\section{BAURAN PEMASARAN}

\section{果}

Place (tempat) :

letak sekolah

yang strategis

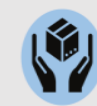

Produk : berupa barang jasa : lulusan Lulusan : banyak meneruskan di mana? prestasi mereka, pekerjaan mereka

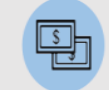

Price : biaya masuk sekolah, vang SPP, vang kegiatan Semua biaya berkaitan dengan jasa dan Fasilitas yang diberikan

\section{SUMBER}

Alma, Buchari . (2004). Manajemen Pemasaran dan Pemasaran Jasa. Bandung, ALFABETA.

Anzizhan, S. (2004). Sistem pengambilan keputusan pendidikan. Jakarta: Grasindo.

Van Brummelen, H. (2006). Berialan dengan tuhan di dalam kelas: pendekatan kristiani untuk pembelajaran. Jakarta: Universitas Pelita Harapan.

\section{SEKOLAH}

Sekolah adalah organisasi formal yang menjelaskan program pendidikan bagi anak dengan tujuan dan aturan yang ielas untuk membina anak yang berkualitas sebagaimana diharapkan oleh masyarakat (Anzizhan, 2004, hal. 26).

Lingkungan belajar yang mendukung, membantu siswa untuk berkontribusi dan merasa diterima serta menghargai bakat unik dan kontribusi para siswa (Van Brummelen, 2006).

Sekolah yang efektif adalah sekolah-sekolah yang mana dewan pengurus dan komisi sekolah, kepala sekolah dan guru-guru, dan orang tua dan siswa mengambil andil dan bekeria sama untuk menerapkan visi yang sama. Bagaimanapun struktur organisasi mereka, sekolah-sekolah yang efektif dapot membina hubungan yang dekat antera guru dan orang tua (Van Brummelen, 2006).

\section{STRATEGI JANGKA PENDEK}

1. Meningkatkan jumlah siswa

2. Promosi sekolah

\section{PROMOSI}

Definisi Sejenis komunikasi yang memberikan penjelasan

promosi yang meyakinkan calon konsumen tentang barang dan jasa. (Alma, 2005)

Tujuan Memperoleh perhatian, mendidik, mengingatkan promosi dan meyakinkan calon konsumen. (Alma, 2005)

\section{TIPS}

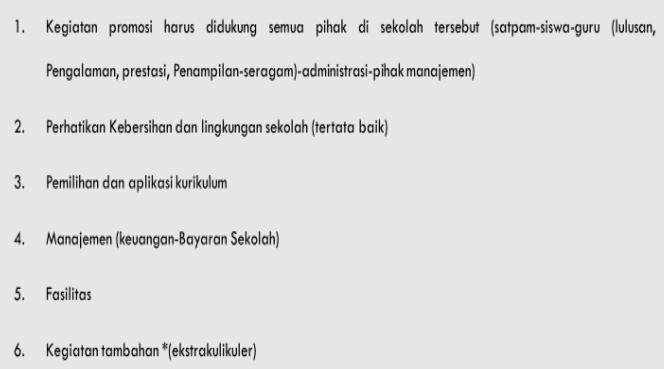



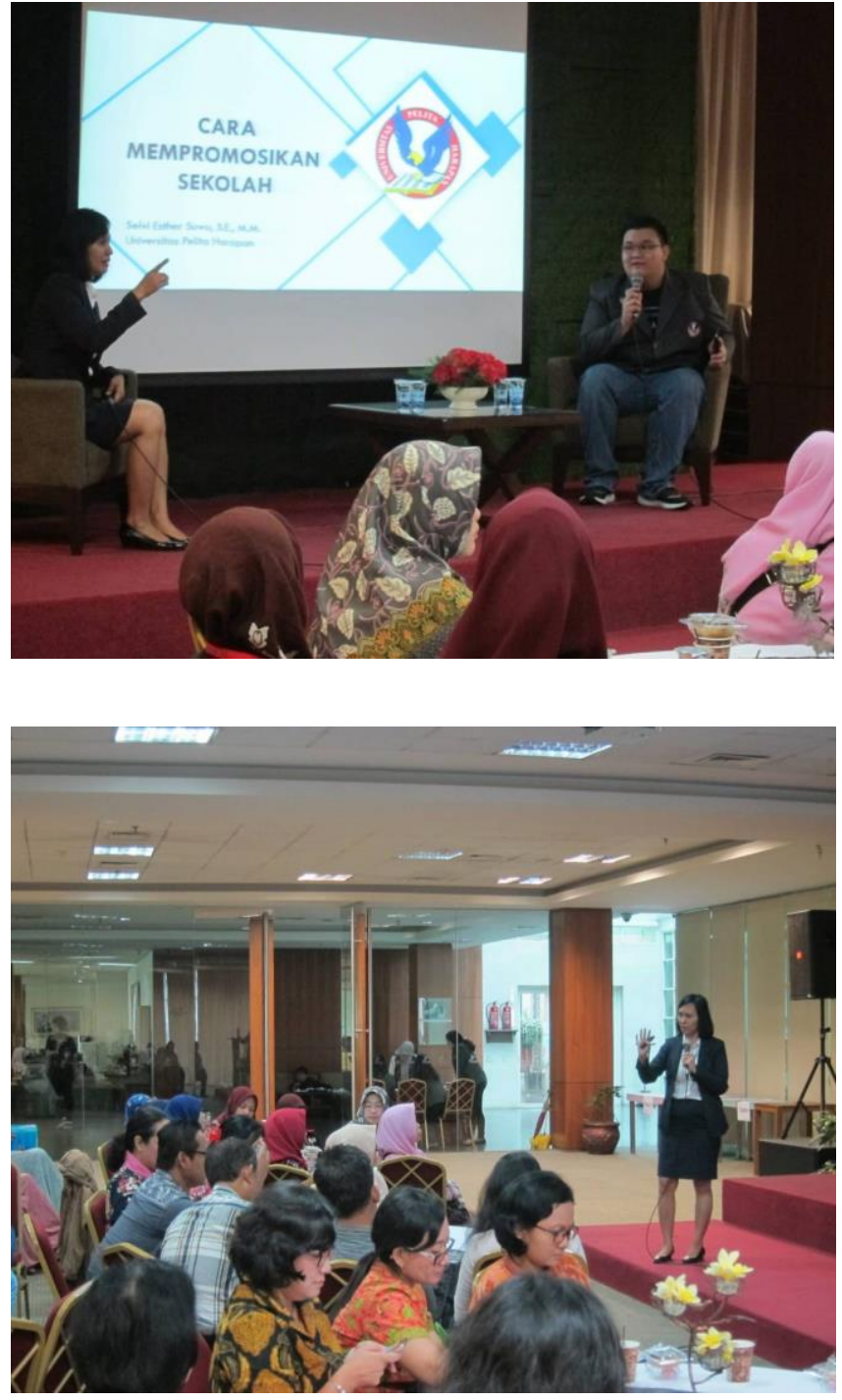

\section{HASIL DAN PEMBAHASAN}

Setelah membawakan materi pembicara memberikan post test untuk mengetahui seberapa tingkat pengetahuan yang diterima peserta mengenai promosi sekolah. Berikut adalah tabel hasil perhitungan kuesionernya.

Tabel 1 Pihak manajemen telah menggunakan promosi untuk memperkenalkan sekolah

\begin{tabular}{|c|c|c|}
\hline Sudah & Kurang & Belum \\
\hline 47 orang & 4 orang & 3 orang \\
\hline
\end{tabular}

Peserta datang dari sekolah-sekolah tangerang dan sekitarnya, sebelum acara ini pembicara ingin
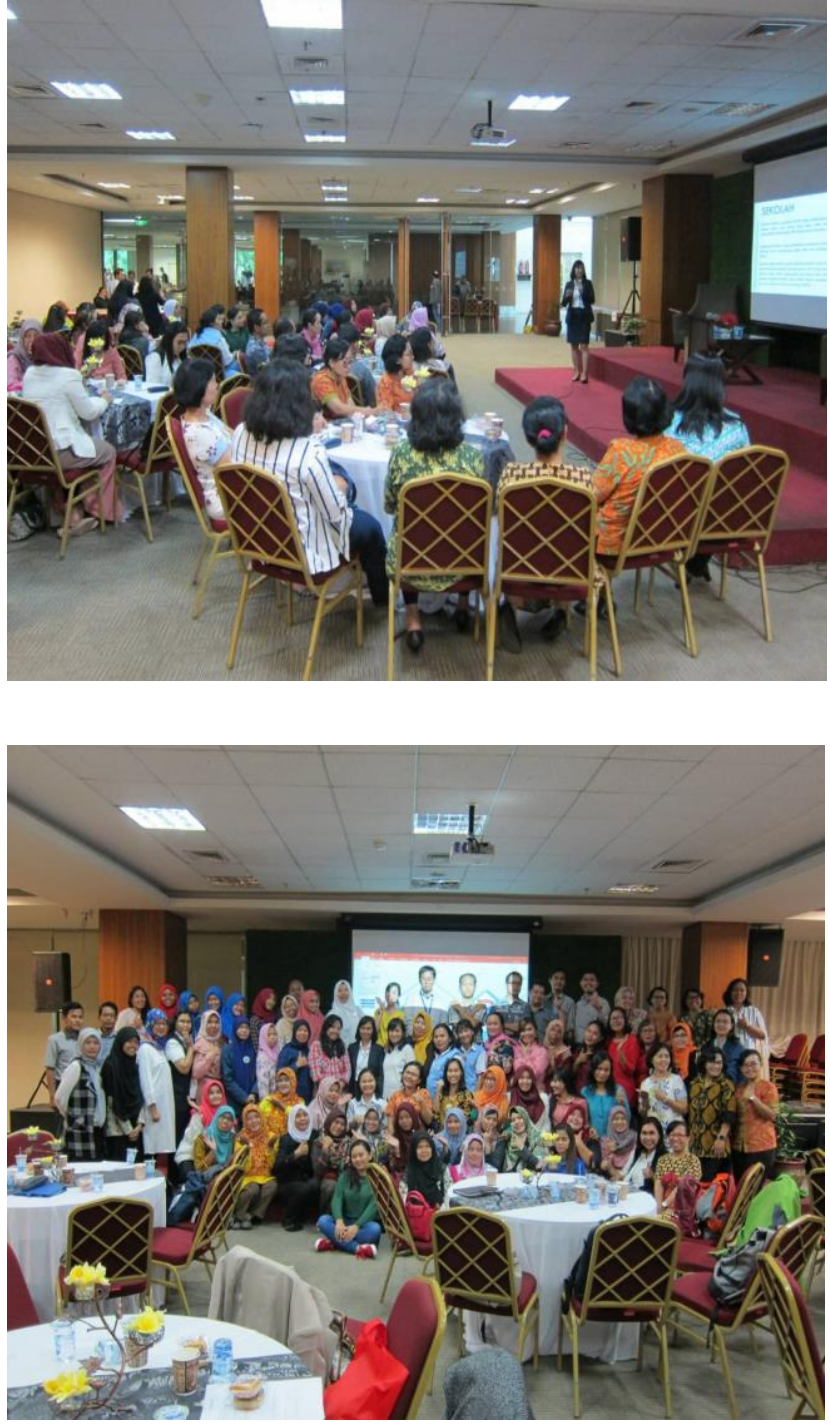

mengetahui apakah pihak manajemen sekolahsekolah tersebut sudah atau belum? Dari data di atas 47 peserta yaitu $47 / 54 \times 100 \%=87 \%$ peserta dalam manajemen sekolah sudah menggunakan promosi untuk memperkenalkan sekolah. Ada $4 / 54 \times 100 \%=7 \%$ yang kurang dan ada $3 / 54 \mathrm{X} 100 \%=5 \%$ yang tidak menggunakan promosi.

Tabel 2 Metode promosi yang digunakan

\begin{tabular}{lc}
\hline Metode Promosi & Jumlah \\
\hline Online/Internet, Media sosial & 25 \\
Spanduk/ Banner & 27
\end{tabular}

Ekonomi, Sosial, dan Budaya 
Brosur

Pertunjukan di Mall, acara-acara sekolah, open house, lomba

Door to door

Mouth to mouth

Free trial

Discount up to

Buletin Sekolah

Iklan (majalah / surat kabar

Kalender / souvenir/ merchandise

Stiker mobil

\begin{tabular}{lllll}
\hline 9 & 43 & 17 & 3 & - \\
\hline
\end{tabular}

Pelatihan ini menurut peserta mereka mendapatkan pengetahuan baru sebanyak 43 peserta mendapatkan beberapa informasi baru, yaitu lebih dari tiga informasi, sebanyak 17 orang peserta mendapatkan dua-tiga informasi baru, 9 peserta mendapatkan semua yang diberikan pembicara adalah informasi baru, sedangkan 3 peserta memperoleh satu informasi dan tidak ada satu pesertapun yang tidak mendapatkan informasi baru.

Tabel 5 Pengetahuan/informasi akan diaplikasikan dalam kegiatan promosi sekolah

Lima metode promosi yang paling banyak digunakan oleh sekolah dalam mempromosikan sekolahnya adalah spanduk $27 / 126 \times 100 \%=21 \%$, brosur 26, internet/media sosial 25 , pertunjukkan di Mall, acara-acara sekolah, open house dan lomba 20, "mouth to mouth" 11.

Tabel 3 Tingkat pengetahuan peserta mengenai materi yang diberikan oleh pembicara

\begin{tabular}{lll}
\hline Sangat mengerti & Mengerti & Biasa \\
\hline 34 orang & 37 orang & 1 orang \\
\hline
\end{tabular}

Melihat tabel di atas 34 orang responden menyatakan sangat mengerti cara mempromosikan sekolah yaitu $34 / 72 \quad X 100 \%=47 \%$, $37 / 72 \times 100 \%=51 \%$ responden menyatakan mengerti cara mempromosikan sekolah, hanya 1 responden yang mengatakan biasa tentang tingkat pengetahuannya. Dapat dikatakan bahwa secara umum peserta mengerti cara mempromosikan sekolah.

Tabel 4 Pengetahuan/informasi baru yang didapatkan pada seminar

\begin{tabular}{lllll}
\hline Semua & Beberap & Dua- & Satu & Tidak \\
Informa & a & tiga & Informa & ada \\
si baru & Informa & Informa & si baru & Informa \\
& si baru & si baru & & si baru \\
\hline
\end{tabular}

Ya

Tidak

\begin{tabular}{ccc}
\hline Ya & & \\
& Tidak & \\
\hline 72 & & 0
\end{tabular}

Semua peserta sebanyak 72 orang mengatakan akan mengaplikasikan pengetahuan yang diperoleh dari pelatihan ini.

Setelah mendapatkan pelatihan promosi sekolah, pembicara ingin tahu promosi apa yang akan digunakan di sekolah peserta, berikut adalah jawabannya : menjalin relasi yang baik dengan orang tua, bersikap ramah dengan lingkungan sekitar, melalui media sosial, mengadakan open house, membuat banner, menampilkan prestasi siswa dan alumni, meningkatkan pelayanan dalam sekolah, membagikan brosur dipasar dadakan/menempel di warung lingkungan sekitar sekolah, membuat flyer/, memperbaiki kualitas, mempromosikan guru-guru berprestasi, memperbaiki fasilitas, melihat kembali kurikulum, visi dan misi sekolah, membuat spanduk, meningkatkan kualitas guru, menambah kegiatan ekstrakulrikuler, mengadakan/mengikuti acara bazar, memperbaiki administrasi, pormosi online berbayar, radio, mengirim siswa ikut lomba. Semua jawaban ini adalah hasil dari pelatihan yang dibawakan oleh pembicara.

Pemilihan promosi yang tepat akan mendorong peningkatan konsumen dalam sekolah. Pihak sekolah juga bukan sekadar memilih metode

Ekonomi, Sosial, dan Budaya $\quad 1086$ 
promosi melainkan lebih dari itu memerhatikan semua aspek di dalam sekolah, seperti kurikulum, pelayanan sehari-hari tentunya juga fasilitas. Kedepannya jika semua sekolah di Indonesia peka dan mau belajar serta mengusahakan peningkatan kualitas ini maka promosi akan sendirinya akan tercipta.

\section{KESIMPULAN}

1. Pelatihan promosi sekolah berjalan baik dan lancar, semua peserta mengerti yang dibawakan pembicara.

2. Peserta mendapatkan pengetahuan baru mengenai promosi sekolah dan akan mengaplikasikannya pada sekolah mereka.

3. Sekolah kedepannya akan memerhatikan promosi yang tepat bagi sekolah dan semua aspek pelayanan serta kualitas sekolah (guru, tenaga administrasi dan fasilitas sekolah) demi kemajuan sekolahnya.

\section{UCAPAN TERIMAKASIH}

Ucapan terimakasih disampaikan kepada Service Learning UPH atas kepercayaan dan kerjasamanya dengan penulis sebagai pembicara pelatihan ini.

\section{REFERENSI}

Buchari, A. (2005). Manajemen Pemasaran dan Pemasaran Jasa (Revisi). Bandung: CV AlFABETA.

Christian, D., Siahaan, H. A. L., \& Wardhani, M. K. (2015). METODE BELAJAR SERVICE LEARNING DI UNIVERSITAS PELITA HARAPAN. Tangerang.

Elliott, G., RUNDLE-THIELE, S., \& Waller, D. (2014). Marketing (Third). Milton, Australia: John Wiley \& Sons.

Kotler, P., \& Armstrong, G. (2008). Prinsip-prinsip Pemasaran Jilid 1 (12th ed.). Jakarta: PENERBIT ERLANGGA.

Kotler, P., Armstrong, G., Ang, S. H., Leong, S. M., Tan, C. T., \& Hon-Ming, O. Y. (2011). PRINCIPLES OF MARKETING AN ASIAN PERSPECTIVE. Jurong: Pearson Education
South Asia Pte Ltd.

Tjiptono, F. (2017). Service Management Mewujudkan- Layanan Prima (edisi 3). Yogyakarta: Penerbit ANDI.

Van Brummelen, H. (2006). Berjalan dengan Tuhan di dalam Kelas Pendekatan Kristiani untuk Pembelajaran. Tangerang: Universitas Pelita Harapan. 